\title{
Giardia duodenalis in feedlot cattle from the central and western United States
}

\author{
Bruce R Hoar*1, Robert R Paul1,3, Jennifer Siembieda ${ }^{1}$, Maria das Gracas \\ C Pereira ${ }^{2}$ and Edward R Atwill ${ }^{2}$
}

Address: 'Department of Medicine and Epidemiology, School of Veterinary Medicine, University of California-Davis, Davis, CA 95616, USA, 2Department of Population Health and Reproduction, School of Veterinary Medicine, University of California-Davis, Davis, CA 95616, USA and ${ }^{3} 810$ Schreider Street, Fort Detrick, Maryland 21702-5000, USA

Email: Bruce R Hoar* - brhoar@ucdavis.edu; Robert R Paul - Robert.r.paul@us.army.mil; Jennifer Siembieda - jensiembieda@ucdavis.edu; Maria das Gracas C Pereira - mpereira@ucdavis.edu; Edward R Atwill - ratwill@ucdavis.edu

* Corresponding author

Published: 2 October 2009

BMC Veterinary Research 2009, 5:37 doi:10.1186/1746-6/48-5-37

This article is available from: http://www.biomedcentral.com/l746-6/48/5/37

(c) 2009 Hoar et al; licensee BioMed Central Ltd.

This is an Open Access article distributed under the terms of the Creative Commons Attribution License (http://creativecommons.org/licenses/by/2.0), which permits unrestricted use, distribution, and reproduction in any medium, provided the original work is properly cited.
Received: 17 September 2008

Accepted: 2 October 2009

\begin{abstract}
Background: Giardia duodenalis is a ubiquitous protozoan parasite that has emerged as a significant opportunistic human pathogen. $G$. duodenalis may have a deleterious effect on animal growth and performance, therefore its potential as a production limiting organism should not be discounted. We therefore undertook this study to determine management and environmental factors in feedlots that influence the prevalence and environmental load of $G$. duodenalis cysts in fecal material deposited by feedlot cattle in the central and western United States.

Results: Twenty two feedlots from 7 states were included in the study, and up to 240 fecal samples were collected from pen floors of up to 6 pens per feedlot. Giardia duodenalis cysts were identified and counted using direct immunofluorescent microscopy. The estimated overall point prevalence of $G$. duodenalis was $19.1 \%$, representing feedlots from a wide range of climates and management systems. Pen-level prevalence varied from 0 to $63.3 \%$, with pen-level shedding estimates ranging from 0 to 261,000 cysts/g feces. Higher environmental temperatures, increased animal density, and increased time in the feedlot were associated with a lower prevalence of $G$. duodenalis. Removing manure before placing a new group of cattle in a pen was associated with a decreased prevalence of $G$. duodenalis in fecal pats. Using coccidiostats as a feed additive was associated with a higher prevalence of Giardia.
\end{abstract}

Conclusion: Management practices could be employed that would limit the probability that feedlot cattle shed $G$. duodenalis in their feces and therefore potentially limit contamination of their environment.

\section{Background}

Giardia duodenalis is a ubiquitous protozoan parasite that has emerged as a significant opportunistic human pathogen. At least seven distinct assemblages (A - G) of G. duodenalis have been identified [1] however only assemblages
A and B are associated with human infections [2]. Giardia infections are usually self-limiting in people with normal immune systems, but can be severe in immuno-compromised individuals [3-5]. Since the infectious dose for susceptible humans may be as low as $10 \mathrm{G}$. duodenalis cysts 
[6] it is important to minimize contact between fecal material containing infectious cysts and water supplies used for municipal, recreational, or irrigation purposes.

While cattle have been found to be primarily infected with the livestock-specific assemblage E genotype, a portion of G. duodenalis infections in ruminants have been attributed to either assemblage A mono-infection [7], to mixed infections with both assemblage A and E [8,9], or to infection with assemblage B [10]. This raises uncertainty over the relative importance of cattle manure as a source of transmission of the parasite to humans; however genotyping data suggest that the public health risk is probably minimal since the livestock genotype predominates in cattle [2,3]. G. duodenalis infection in dairy cattle had been studied because the confinement practices of dairies has been linked with increased G. duodenalis infection and reinfection rates of calves $[11,12]$. The focus of research then was turned to beef cattle on pastures and Giardia cysts were found in agricultural run-off at an increased concentration during peak calving time [13]. Further studies attempted to determine the prevalence of Giardia in cattle coming from pastures into a confinement operation [14]. Young cattle are more likely to shed G. duodenalis cysts than adult cattle. In particular, previous studies have found that the prevalence of $G$. duodenalis shedding for beef and dairy calves up to 9 months ranges from $17-55 \%$ and for adult beef and dairy cattle ranges from $0-17 \%$ $[13,15-19]$. It is uncertain whether infection of ruminants with G. duodenalis is associated with clinical disease [7], but infection may be associated with the occurrence of diarrhea and ill-thrift in calves $[8,12]$ and severe weight loss in lambs [20]. An experimental study using SPF lambs has been shown that $G$. duodenalis can have a deleterious effect on animal growth and performance [21], therefore its potential as a production limiting organism should not be discounted.

Much of the variation in reports of prevalence is likely due to the differences in populations of cattle studied, which include the type of operation (beef versus dairy), age distribution of cattle, and variation in management practices [22]. It has been shown that the rate of environmental loading of G. duodenalis per animal unit or mass of fecal material is conditional on the underlying age distribution of the herd [15-17]. Other studies found that the prevalence of Giardia infection was not associated with factors such as calf management, confinement, manure accumulation, farm hygiene, or duration of the calving season $[14,19,23]$.

Presently, little is known about the prevalence of G. duodenalis in cattle in commercial feedlots. Large numbers of cattle are concentrated in feedlots across the United States, leading to high-volume point sources of fecal waste. In order to develop management plans to reduce the potential for waterborne transmission of G. duodenalis, a valid estimate of the prevalence of infection and number of cysts present in the fecal material deposited by feedlot cattle is required. Therefore, we undertook this study to determine management and environmental factors in feedlots that influence the prevalence and environmental load of G. duodenalis cysts in fecal material deposited by feedlot cattle in the central and western United States.

\section{Methods}

\section{Feedlot selection and fecal sampling}

One to 4 feedlots from selected states that were deemed by collaborators to be representative of feeding operations in those states were identified for inclusion in the study. Factors considered included location, animal capacity, type of cattle fed, and management system. A total of 22 feedlots in 7 states (California, Washington, Colorado, Oklahoma, Texas, Nebraska, and South Dakota) were eventually enrolled. Feedlots in different states were sampled in sequence so that fecal samples were collected from feedlots with a variety of animal husbandry practices both within and across states and across different climatic conditions and seasons. Approximately 240 fecal samples were collected at each feedlot, from between 2 and 6 pens of cattle. Samples were collected from a randomly selected pen of cattle that had recently arrived to the feedlot, a randomly selected pen of cattle nearing their harvest date, and the remaining pens were randomly selected from across the feedlot. One-hundred-gram fecal samples were collected from freshly-deposited fecal pats, placed on ice packs, and shipped by overnight courier to the Veterinary Medicine Teaching and Research Center, Tulare, CA within 24 hours of collection. A questionnaire related to feedlot and pen management was administered to the feedlot manager at the time of fecal sampling. The following data was recorded: number of animals in the pen, temperature and precipitation during the previous month, animal class (heifer, steer, bull, beef, dairy), water source, pen size, days in feedlot, coccidiostats in feed, days between lots of cattle, pen cleaning/scraping frequency, presence of a cover for the cattle, percent concentrate in feed, primary concentrate used, source of cattle (auction, ranch derived, combination), and water/feed trough cleaning frequency and method.

\section{Detection and enumeration of G. duodenalis cysts}

Direct immunofluorescent microscopy (DFA) was used for detecting and enumerating $G$. duodenalis cysts as previously described [24]. Briefly, five grams of each fecal sample were mixed with $40 \mathrm{~mL}$ of deionized water and washed through folded 2-ply gauze. Fecal suspensions were centrifuged at $1,000 \times \mathrm{g}$ for 10 minutes, supernatants aspirated, and the residual fecal sediments resuspended $1: 1(\mathrm{v} / \mathrm{v})$ in deionized water to a final volume of 3 to $5 \mathrm{ml}$. 
Ten $\mu$ l of fecal suspension (average weight $=11.7 \mathrm{mg}$ ) was smeared onto glass slides and dried overnight. Detection of cysts was performed using the direct immunofluorescent assay (Merifluor Cryptosporidium/Giardia detection kit, Meridian Diagnostic, Inc., Cincinnati, OH). The entire slide was scanned at $\times 200$ magnification. The total number of $G$. duodenalis cysts was recorded for each smear.

To determine percent recovery for immunofluorescent microscopy, we collected three fecal samples from beef feedlot cattle that tested negative for $G$. duodenalis and added purified wild-type dairy calf $G$. duodenalis cysts to a final concentration of either 100, 1000, or 10,000 oocysts/L. Three replicates per concentration per fecal sample were used for a total of 26 fecal samples. The immunofluorescent microscopy procedure was then performed as described above. Percent recovery was estimated by fitting a negative binomial regression model to the observed number of oocysts, with the number of spiked or expected oocysts functioning as the offset variable and fecal identification as a cluster variable due to using three replicates per concentration per fecal sample [25]. The estimated percent recovery for enumerating $G$. duodenalis cysts using the immunofluorescent microscopy procedure was 36.2\% (95\% CI, 28.4\% - 46.2\%). The estimated concentration of $G$. duodenalis was therefore calculated by dividing the number of cysts observed by the average amount of fecal material on each slide $(0.0117$ grams) multiplied by 0.362 , the estimated cyst recovery rate.

\section{Statistical Procedures and Modeling}

The prevalence of $G$. duodenalis was calculated by type of feedlot pen, management practices, and climate factors. Pen order was categorized into three groups; entry pens (nutrition based primarily on forages), middle pens (feedlot diets transition from high roughage to high concentrates), and exit pens (diets containing a high proportion of concentrates). The concentration of cysts in each positive sample was placed into categories of fecal cyst load. The prevalence of $G$. duodenalis positive samples was calculated for each category of fecal cyst load by pen order. Differences in proportion G. duodenalis positive between groups were assessed using a univariate logistic regression.

A logistic regression model was created using a commercial software program (Egret ${ }^{\circledR}$ for Windows, Cytel Software Corporation, Cambridge, MA) to identify cattle characteristics (such as sex, breed, and source), farm management practices, and climate factors associated with the presence of $G$. duodenalis cysts in fecal samples from feedlot cattle. Descriptive statistics were performed to determine variable ranges, the extent of outliers, and to check for normality of continuous variables. All potential risk factors were initially screened for their association with the presence of G. duodenalis cysts using univariate logistic regression. Variables with a Pearson's chi-square statistic of $\mathrm{p} \leq 0.25$ were offered entry into the model building process. Two-way interaction variables were created from this list and offered for entry. A forward stepping approach was used to develop the logistic regression model, with $\mathrm{p} \leq 0.05$ as determined by a likelihood ratio test set as the criterion for inclusion of the variable in the final model. The variable "pen" was included as a random effect term in the final model because fecal samples from the same pen were not considered to be independent.

\section{Results}

A total of 5,260 fecal samples were collected from 22 feedlots in California, Colorado, Nebraska, Oklahoma, South Dakota, Texas, and Washington. The overall proportion of fecal samples containing detectable $G$. duodenalis cysts was $19.1 \%(1,006 / 5,260)$; prevalence within pens varied from $0 \%$ to $63.3 \%$, while prevalence within feedlots varied from $5.4 \%$ to $43.6 \%$ (Table 1 ). The proportion of G. duodenalis positive fecal pats in entry pens was $26.1 \%(\mathrm{n}=$ $1401)$, in mid-duration pens was $17.2 \%(\mathrm{n}=2488)$, and in pens nearing harvest was $15.5 \%(n=1371)$. The prevalence for entry pens was significantly higher than in middle and exit pens $(\mathrm{p}<0.001)$.

The distribution of fecal concentration of G. duodenalis by pen type is shown (Figure 1). There were a greater proportion of fecal samples from entry pens in each fecal concentration category, except for the greater than $10^{6}$ category. Twelve fecal samples ( $0.2 \%$ of all samples) were estimated to have more than $10^{6} \mathrm{G}$. duodenalis cysts per gram of feces. These fecal samples were from 6 different feedlots; four of these high intensity fecal samples were from the same pen of exit cattle.

The proportion of fecal samples positive for G. duodenalis was inversely associated with temperature; prevalence was greatest in feedlots which had had the coldest temperatures in the past month, and least in feedlots which had had the hottest temperatures in the past month (Figure 2).

Almost all feedlots had a dirt surface, used feed bunks for feeding (as opposed to feeding on the dirt/floor), fed corn as their primary concentrate, had no cover for the cattle, and used wells as their primary water source; these variables are not included in the logistic regression model due to a lack of variation. The final logistic regression model included number of days in the feedlot, average temperature during the previous month, animal density within pens, whether manure was removed between lots of cattle, and whether a coccidiostat was included in the ration (Table 2). Several factors were not associated with a sample testing positive for $G$. duodenalis including type of 
Table I: Prevalence and intensity of Giardia duodenalis cysts in fecal samples from beef cattle located on 22 feedlots from central and western United States.

\begin{tabular}{|c|c|c|c|}
\hline State/Month of sampling & Feedlot prevalence' (sample size) & Range of prevalence by pen ${ }^{2}$ & $\begin{array}{l}\text { Range of intensity of fecal shedding } \\
\text { by pen }{ }^{2} \text { (cysts/g feces) }\end{array}$ \\
\hline \multicolumn{4}{|l|}{ Texas } \\
\hline January & $9.3(226)$ & $0.0--33.3$ & $0--31,960$ \\
\hline April & $5.4(242)$ & $0.0--8.3$ & $0--3,5 \mid 3$ \\
\hline September & $11.0(236)$ & $0.0--16.7$ & $0--15,429$ \\
\hline \multicolumn{4}{|l|}{ Oklahoma } \\
\hline January & $23.8(240)$ & $1.7--56.7$ & $46--26,955$ \\
\hline May & $21.7(240)$ & $11.7--36.7$ & $436--51,430$ \\
\hline January & $14.6(239)$ & $0.0-31.7$ & 0 -- 2,089 \\
\hline \multicolumn{4}{|l|}{ California } \\
\hline August & $16.7(245)$ & | $3.3-20.0$ & $4,519--58,663$ \\
\hline February & $20.0(240)$ & $10.0-38.3$ & $298--5,166$ \\
\hline September & $7.5(240)$ & $3.3--11.7$ & $390--3,605$ \\
\hline January & $6.4(235)$ & $3.4-13.3$ & $47--|6| 4 \mid$, \\
\hline \multicolumn{4}{|l|}{ Washington } \\
\hline October & $34.2(240)$ & $25.0--52.5$ & I,722 -- 261,710 \\
\hline \multicolumn{4}{|l|}{ Colorado } \\
\hline September & $20.4(240)$ & $11.7--33.3$ & $1,079--219,406$ \\
\hline March & $30.9(236)$ & $20.0--45.0$ & $\mathrm{I}, 446--7,783$ \\
\hline July & $13.9(244)$ & $8.3--16.9$ & $184--22,298$ \\
\hline January & $18.8(240)$ & $5.0--45.0$ & II 5 -- 22,248 \\
\hline \multicolumn{4}{|l|}{ Nebraska } \\
\hline November & $25.0(240)$ & $3.3--63.3$ & $161--144,327$ \\
\hline April & $19.5(236)$ & $8.3--30.0$ & $94 \mid--7,278$ \\
\hline September & $12.2(238)$ & $0.0--25.0$ & 0 -- 39,698 \\
\hline \multicolumn{4}{|l|}{ South Dakota } \\
\hline August & $23.3(240)$ & $11.7--38.3$ & $918--10,952$ \\
\hline March & $43.6(243)$ & $26.7--55.0$ & 3,306 -- 7,026 \\
\hline July & $25.8(240)$ & $21.7-28.3$ & $689--2,112$ \\
\hline January & I5.8 (240) & $10.0--16.7$ & $276--1,515$ \\
\hline
\end{tabular}

Overall total

$19.1(5,260)$

I Fecal samples from each feedlot were collected from two to six pens of cattle, stratified by time on feed (entry, middle, exit)

2 Prevalence of fecal samples with Giardia duodenalis cysts and their mean intensity (cysts/g feces) calculated at the level of pen

roughage fed, percent energy concentrate in current ration, feed bunk cleaning methods, source of cattle, and whether cattle come from single or multiple sources.

The predicted prevalence of G. duodenalis by the number of days in the feedlot and by temperature is shown in Figures 3 and 4 (based on the final regression model). These show that increasing days in the feedlot and increasing ambient air temperature were associated with a reduction in Giardia prevalence, that feeding a coccidiostat increases the prevalence over not feeding a coccidiostat, and that manure removal prior to placing cattle in a pen is associated with reduced prevalence of infection.

\section{Discussion}

In this sample of fecal material from feedlots in the central and western United States, the point prevalence of G. duodenalis was $19.1 \%$, with $26.1 \%$ of samples from newlyarrived cattle and $15.5 \%$ of samples from cattle near harvest testing positive. While the cumulative infection rate with Giardia may reach $100 \%$ in range beef calves [14], previous studies of beef cattle on pasture reported point prevalence of G. duodenalis in $6.5 \%$ and $11 \%$ of fecal samples $[23,26]$. This suggests that feedlot confinement may create the conditions that allow for a higher point prevalence of Giardia infection as compared to pasture settings, especially when cattle first enter the feedlot. As cattle 


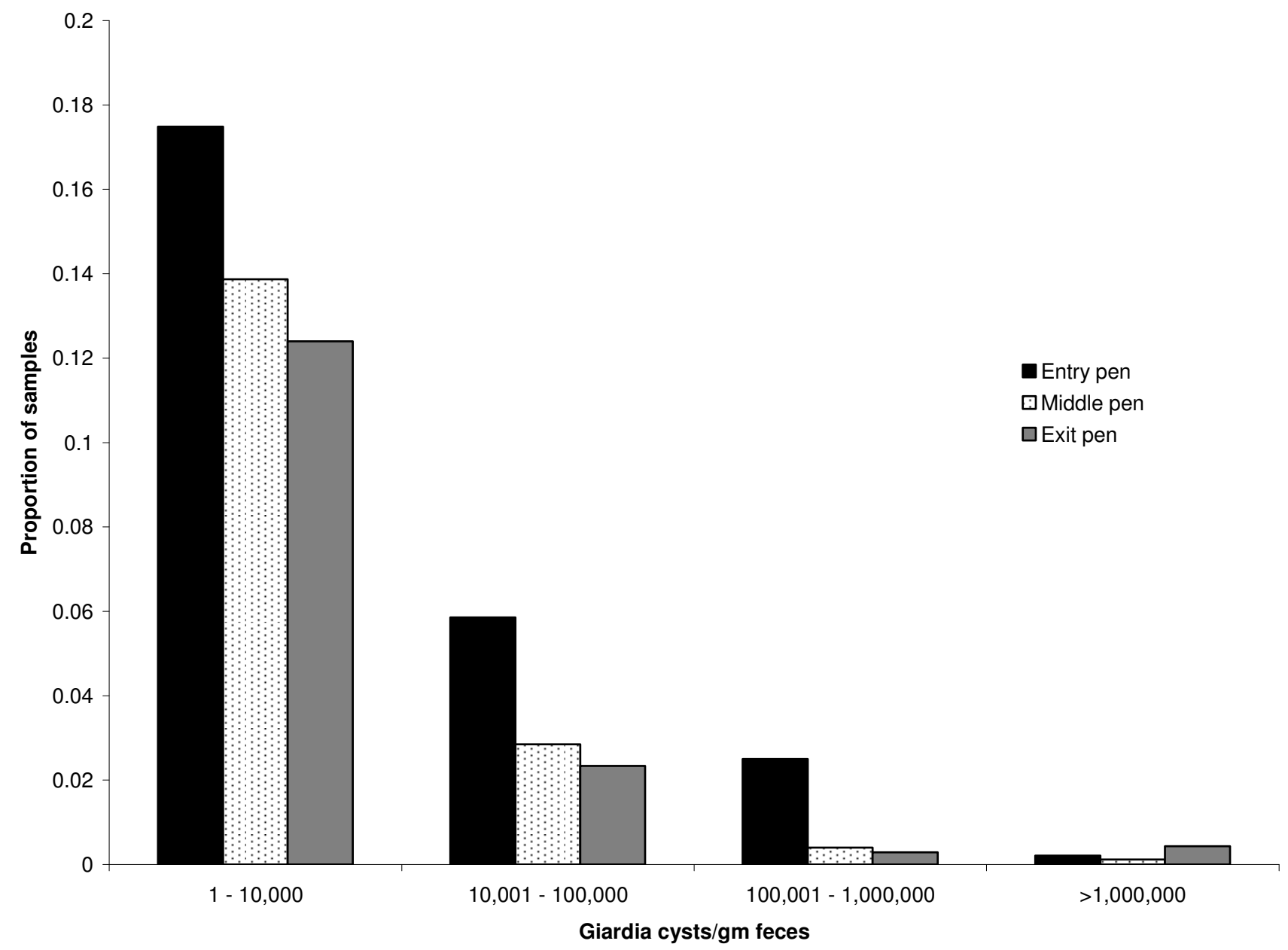

Figure I

Proportion of Giardia duodenalis positive fecal samples from central and western United States, classified by pen order and concentration of cysts. Entry pens are where cattle first enter the feedlot from pasture, middle pens are where feedlot diets transition from high roughage to high concentrates, and exit pens are where cattle are fed high concentrate rations immediately prior to harvest. Negative fecal samples are not shown.

remain in the feedlot, prevalence is reduced. A longitudinal study in calves found a cumulative prevalence of $100 \%$, with $85 \%$ prevalence in the first month, decreasing to $21 \%$ prevalence in months $6-7$ [14]. While an individual animal seems very likely to become infected at some point in their life, the current study provides a valuable estimate of point prevalence at various times during the feeding period.

Results from this study indicate that hot climates are associated with reduced prevalence of $G$. duodenalis in pen fecal deposits; our model predicted that as temperature increased the odds of detecting Giardia cysts decreased by $2.2 \%$ per ${ }^{\circ} \mathrm{C}$. This may result from the desiccation of Giardia cysts in the fecal material by the high temperatures, thereby reducing transmission among cattle within a pen and the probability that a freshly collected fecal pat would contain cysts. Bingham et al. studied the physical factors involved with excystation of Giardia and viability in varying temperatures [27]. Cysts survive up to 77 days in $8^{\circ} \mathrm{C}$, $5-24$ days in $21^{\circ} \mathrm{C}$, and not longer than 4 days in $37^{\circ} \mathrm{C}$ under laboratory conditions. The internal temperature of fecal pats can increase to as high as $70^{\circ} \mathrm{C}[28]$ which further affects the viability of Giardia cysts and decreases the potential for infection of penmates. Other researchers have demonstrated that Giardia cyst viability was compromised by shearing forces generated during freeze-thaw cycles, while lower temperatures were protective of cysts [29]. The prevalence of Giardia in feedlots that had an average temperature range of 1 to $10^{\circ} \mathrm{C}$, which may reflect 


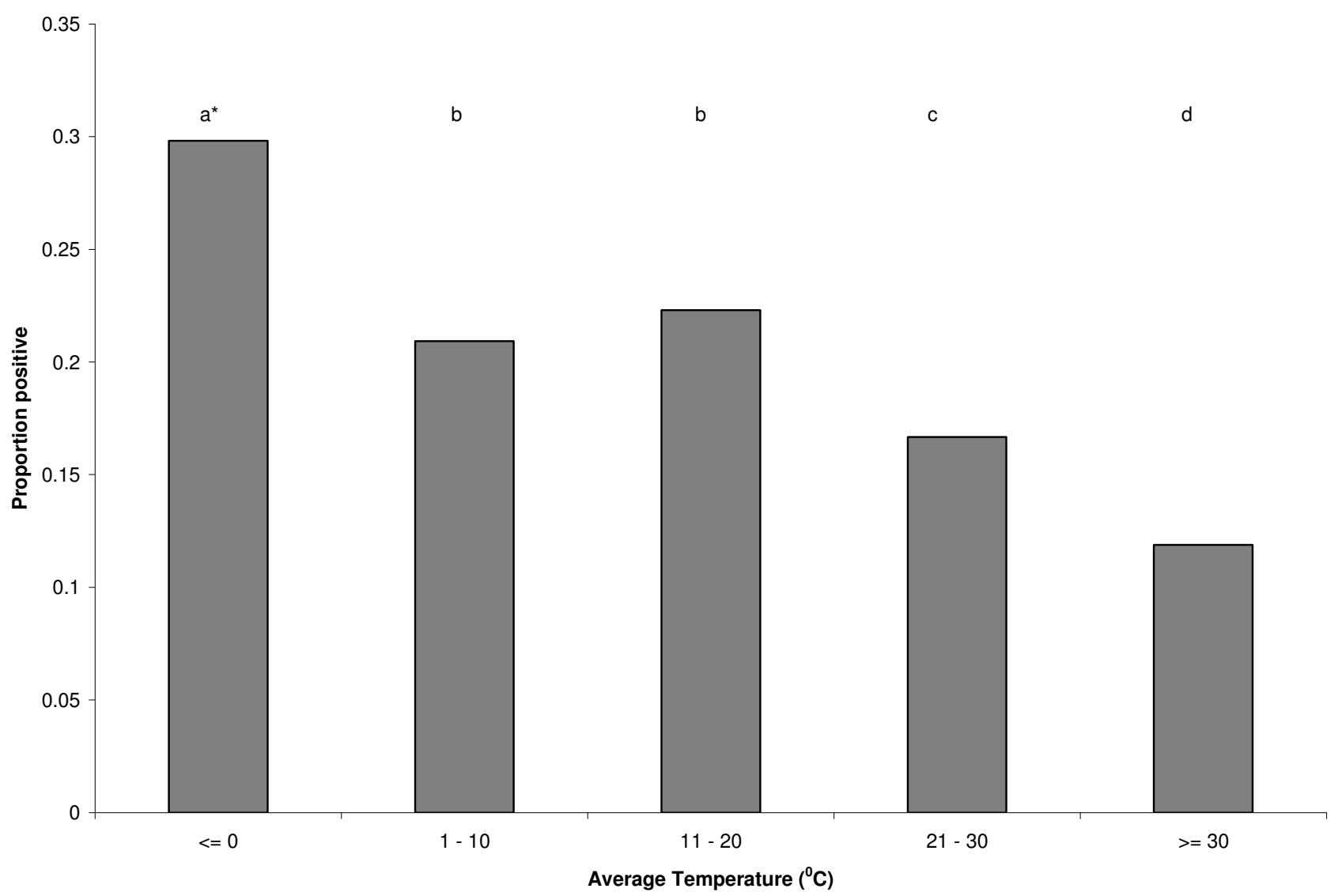

Figure 2

Proportion of fecal samples from feedlot pen floors positive for Giardia duodenalis by average temperature in the prior month from central and western United States. Categories with different superscripts are significantly different $(P<0.05)$.

potential freeze/thaw conditions, was significantly lower than feedlots with an average temperature range below freezing (Figure 2). If fewer cysts are viable infection rates in a feedlot are likely to be reduced. Another possible explanation is that at the coldest temperatures, animals are more likely to cluster together more closely, thereby increasing the effective animal density and transmission potential. The regression model supports the studies above by demonstrating a negative relationship between temperature and Giardia positive cattle (Figure 4). All of the feedlots included in this study were outdoors (typical of central and western United States), therefore we cannot comment on the possible effect of temperature in indoor facilities.

Increased pen area per animal was found to have a slight positive association with prevalence of $G$. duodenalis (Table 2). While this finding is counterintuitive, the magnitude of the association was small, and may represent the effect of other unmeasured factors that confound the relationship between animal density and shedding.

Coccidiostats, which include monensin, lasalocid, and decoquinate, are feed additives commonly incorporated into feedlot rations in order to control infection with various Eimeria spp. However, the primary reason for including most coccidiostats in feedlot rations is to improve feed to gain conversion. In this study, feeding a coccidiostat in the ration was associated with an increased prevalence of infection with $G$. duodenalis. These feed additives selectively inhibit certain ruminal microorganisms, thereby altering fermentation efficiency and end products available for absorption and performance [30]. We speculate that the alteration in the rumen environment may influence survival and reproduction of this parasite. Another possible explanation would be that if the feedlot believes that use of coccidiostats is warranted, then conditions may be appropriate for transmission of coccidiosis, and 


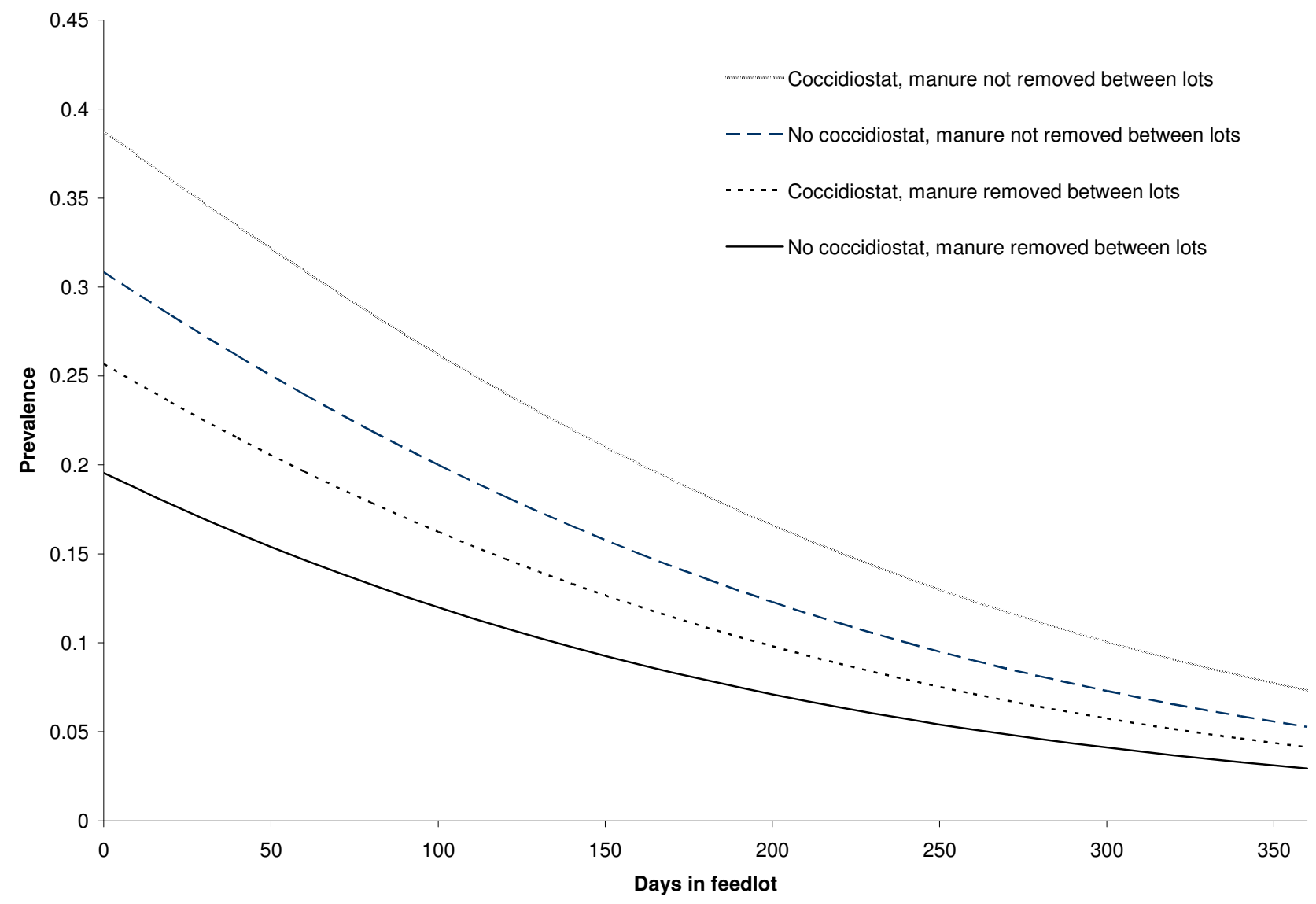

Figure 3

Predicted G. duodenalis prevalence in feedlot cattle from central and western United States by number of days cattle have been in the feedlot.

these conditions may be similar for transmission of giardiasis. This observation warrants further investigation.

Removing manure prior to placing a new group of cattle in a pen was found to be associated with a decreased prevalence of G. duodenalis (Table 2). Physical removal of potentially infective cysts before exposing a new group of cattle to the pen is a management practice that could reduce the potential for cyst transmission.

While there are reports examining the environmental load of Cryptosporidium parvum [22,23,25], there are few published studies measuring the environmental load of Giardia cysts to compare the results from this research. The current study found that feedlot cattle can shed G. duodenalis in the range of tens of millions to hundreds of millions of cysts per animal per day. Ralston et al. performed a longitudinal study that demonstrated a decline in prevalence of G. duodenalis over time and attributed the higher prevalence in young cattle entering the feedlot to a temporary relaxation of immunity from the stresses of weaning and being shipped to a feedlot [14]. The current logistic regression model supports this hypothesis by showing a negative correlation between days in the feedlot and the number of Giardia positive cattle (Figure 3). Further support is confirmed in Figure 1, demonstrating a larger number of cattle infected with Giardia in the entry pens, as compared with middle and exit pens. These findings may indicate that many animals stop shedding Giardia cysts as the animal ages and the duration of their stay at a feedlot lengthens.

We found a small percentage of fecal pats containing a high concentration of cysts. These cattle were found from all stages of the feeding period, which may provide evidence for the existence of Giardia "super-shedders". Researchers have noted this same phenomenon of cattle shedding high concentrations of Escherichia coli O157:H7 and Mycobacterium avium spp. paratuberculosis and have put forth the concept of super-shedders and heavy-shedders, respectively [31-35]. While the proportion of cattle shedding greater than 1 million cysts/g feces was small, 


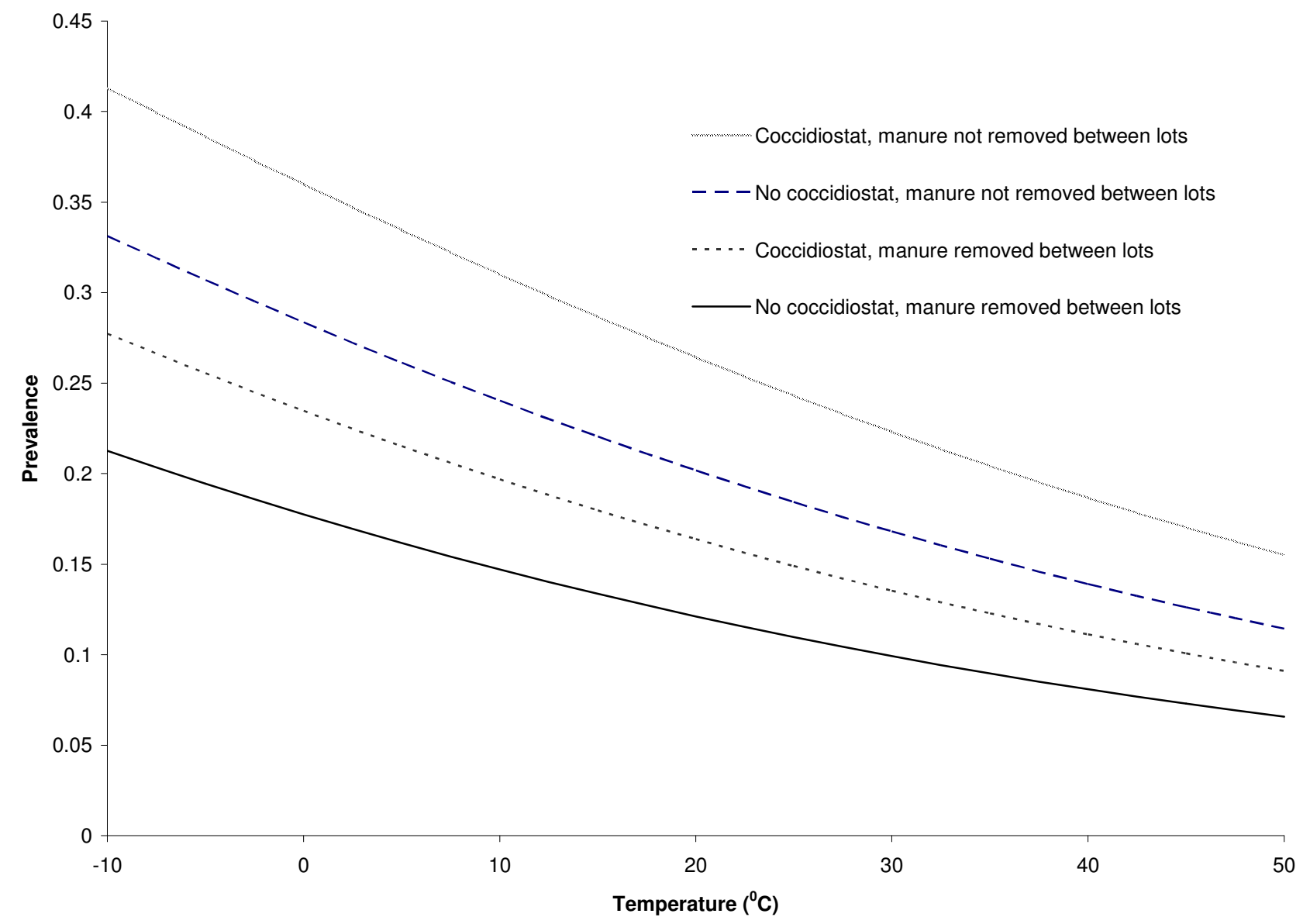

\section{Figure 4}

Predicted Giardia prevalence in feedlot cattle from central and western United States by average temperature of the previous 30 days.

Table 2: Results of a random effects logistic regression model examining factors associated with presence of Giardia duodenalis in cattle feces from feedlots from central and western United States.

\begin{tabular}{|c|c|c|}
\hline Predictor & Odds Ratio (95\% confidence interval) & $P$ - value \\
\hline Days in feedlot & $0.994(0.991,0.997)$ & $<0.001$ \\
\hline Avg. Temperature $\left({ }^{\circ} \mathrm{C}\right)$ & $0.978(0.965,0.991)$ & $<0.001$ \\
\hline Pen density ( $\left.\mathrm{m}^{2} / \mathrm{head}\right)$ & $1.001(1.000,1.002)$ & 0.02 \\
\hline \multicolumn{3}{|l|}{ Coccidiostat in feed } \\
\hline Yes & Referent category & \\
\hline No & $0.704(0.501,0.989)$ & 0.04 \\
\hline Manure removal between lots & Referent category & \\
\hline Yes & $1.83(1.31,2.57)$ & \\
\hline No & & $<0.001$ \\
\hline
\end{tabular}


these cattle potentially represent a significant source of cysts that could potentially contaminate the feedlot environment.

\section{Conclusion}

Recent evidence indicates that cattle are most commonly infected with the non-zoonotic livestock genotype of $G$. duodenalis which limits their role as reservoirs of giardiasis in humans $[2,3,26]$. Nevertheless, given the uncertainty over whether infection with $G$ duodenalis has any adverse clinical consequences in cattle, knowledge of prevalence and risk factors for shedding is important in order to generate management plans. While grazing on pasture may not concentrate cattle and cysts, a feedlot setting may create a sufficient concentration of fecal deposits on a limited area of land; therefore it is recommended that feedlot fecal waste management plans be implemented in order to minimize the potential for environmental contamination with this and other potential pathogens.

\section{Authors' contributions}

$\mathrm{BH}$ helped conceive the project and assisted in writing initial grant application, provided input and advice on statistical modeling, and revised the manuscript. RP assisted in developing statistical models, drafted the initial manuscript. JS performed initial descriptive statistics, and provided input into the initial manuscript. MP performed all laboratory analyses, provided editing for manuscript. EA wrote final draft of grant, supervised all sampling and data collection, assisted in statistical concepts, and edited the final manuscript. All authors read and approved the final manuscript

\section{Acknowledgements}

The authors acknowledge the contributions of C. Elmi, W.B. Epperson, R. Smith, L.V. Carpenter, and D.A. Dargatz for technical assistance and in identifying feedlot collaborators.

Funding:

Although this research described in this article has been funded wholly by the United States Environmental Protection Agency through grant R828038-0I0 to E.R. Atwill, it has not been subjected to the Agency's required peer and policy review and therefore does not necessarily reflect the views of the Agency and no official endorsement should be inferred. The study sponsors had no role in the study design, data collection, analysis and interpretation of the data or in the writing of the manuscript.

\section{References}

I. Monis PT, Andrews RH, Mayrhofer G, Ey PL: Genetic diversity within the morphological species Giardia intestinalis and its relationship to host origin. Infect Genet Evol 2003, 3:29-38.

2. Caccio SM, Ryan U: Molecular epidemiology of giardiasis. Mol Biochem Parasitol 2008, 160:75-80.

3. Hunter PR, Thompson RC: The zoonotic transmission of Giardia and Cryptosporidium. Int J Parasitol 2005, 35: I I8I-II 90.

4. Savioli L, Smith H, Thompson A: Giardia and Cryptosporidium join the 'Neglected Diseases Initiative'. Trends Parasitol 2006, 22:203-208.
5. Wong B: Parasitic diseases in immunocompromised hosts. Am J Med 1984, 76:479-4866.

6. Rendtorff RC: The experimental transmission of human intestinal protozoan parasites. II. Giardia lamblia cysts given in capsules. Am J Hyg 1954, 59:209-220.

7. O'Handley RM, Olson ME: Giardiasis and cryptosporidiosis in ruminants. Vet Clin North Am Food Anim Pract 2006, 22:623-643.

8. Geurden T, Geldhof P, Levecke B, Martens C, Berkvens D, Casaert S, Vercruysse J, Claerebout E: Mixed Giardia duodenalis assemblage A and E infections in calves. Int J Parasitol 2008, 38:259-264.

9. Feng $Y$, Ortega $Y$, Cama V, Terrel J, Xiao L: High intragenotypic diversity of Giardia duodenalis in dairy cattle on three farms. Parasitol Res 2008, 103:87-92.

10. Coklin T, Farber J, Parrington L, Dixon B: Prevalence and molecular characterization of Giardia duodenalis and Cryptosporidium spp. in dairy cattle in Ontario, Canada. Vet Parasitol 2007, I 50:297-305.

II. Ruest N, Faubert GM, Couture Y: Prevalence and geographical distribution of Giardia spp. and Cryptosporidium spp. in dairy farms in Quebec. Can Vet J 1998, 39:697-700.

12. O'Handley RM, Cockwill C, McAllister TA, Jelinski M, Morck DW, Olson ME: Duration of naturally acquired giardiosis and cryptosporidiosis in dairy calves and their association with diarrhea. J Am Vet Med Assoc 1999, 21 4:391-396.

13. McAllister TA, Olson ME, Fletch A, Wetzstein M, Entz T: Prevalence of Giardia and Cryptosporidium in beef cows in southern Ontario and in beef calves in southern British Columbia. Can Vet J 2005, 46:47-55.

14. Ralston BJ, McAllister TA, Olson ME: Prevalence and infection pattern of naturally acquired giardiasis and cryptosporidiosis in range beef calves and their dams. Vet Parasitol 2003, I 1 4:1 I3-122.

15. Fayer R, Trout JM, Graczyk TK, Lewis EJ: Prevalence of Cryptosporidium, Giardia and Eimeria infections in post-weaned and adult cattle on three Maryland farms. Vet Parasitol 2000, 93:103-II2.

16. Wade SE, Mohammed HO, Schaaf SL: Prevalence of Giardia sp. Cryptosporidium parvum and Cryptosporidium andersoni (syn. C. muris) [correction of Cryptosporidium parvum and Cryptosporidium muris (C. andersoni)] in 109 dairy herds in five counties of southeastern New York. Vet Parasitol 2000, 93: I- I I.

17. Huetink RE, Giessen JW van der, Noordhuizen JP, Ploeger HW: Epidemiology of Cryptosporidium spp. and Giardia duodenalis on a dairy farm. Vet Parasitol 2001, 102:53-67.

18. Appelbee AJ, Frederick LM, Heitman TL, Olson ME: Prevalence and genotyping of Giardia duodenalis from beef calves in Alberta, Canada. Vet Parasitol 2003, I I 2:289-294.

19. Gow S, Waldner C: An examination of the prevalence of and risk factors for shedding of Cryptosporidium spp. and Giardia spp. in cows and calves from western Canadian cow-calf herds. Vet Parasitol 2006, 137:50-61.

20. Aloisio F, Filippini G, Antenucci P, Lepri E, Pezzotti G, Caccio S, Pozio E: Severe weight loss in lambs infected with Giardia duodenalis assemblage B. Vet Parasitol 2006, I 42: I54-I58.

21. Olson ME, McAllister TA, Deselliers L, Morck DW, Cheng KJ, Buret $A G$, Ceri $H$ : The effect of giardiasis on production in a domestic ruminant (sheep) model. Am J Vet Res 1995, 56:1470-1474.

22. Atwill ER, Hoar B, das Gracas Cabral Pereira M, Tate KW, Rulofson $F$, Nader G: Improved quantitative estimates of low environmental loading and sporadic periparturient shedding of Cryptosporidium parvum in adult beef cattle. Appl Environ Microbiol 2003, 69:4604-46I0.

23. Hoar BR, Atwill ER, Elmi C, Farver TB: An examination of risk factors associated with beef cattle shedding pathogens of potential zoonotic concern. Epidemiol Infect 200I, I 27:147-I55.

24. Pereira MD, Atwill ER, Jones T: Comparison of sensitivity of immunofluorescent microscopy to that of a combination of immunofluorescent microscopy and immunomagnetic separation for detection of Cryptosporidium parvum oocysts in adult bovine feces. Appl Environ Microbiol 1999, 65:3236-3239.

25. Atwill ER, Pereira MD, Alonso LH, Elmi C, Epperson WB, Smith R, Riggs W, Carpenter LV, Dargatz DA, Hoar B: Environmental load of Cryptosporidium parvum oocysts from cattle manure in feedlots from the central and western United States. J Environ Qual 2006, 35:200-206. 
26. Olson ME, O'Handley RM, Ralston BJ, McAllister TA, Thompson RCA: Update on Cryptosporidium and Giardia infections in cattle. Trends Parasitol 2004, 20: 185-191.

27. Bingham AK, Jarroll EL Jr, Meyer EA, Radulescu S: Giardia sp.: physical factors of excystation in vitro, and excystation vs eosin exclusion as determinants of viability. Exp Parasitol 1979, 47:284-291.

28. Li X, Atwill ER, Dunbar LA, Jones T, Hook J, Tate KW: Seasonal temperature flucuations induces rapid inactivation of Cryptosporidium parvum. Environ Sci Technol 2005, 39:4484-4489.

29. Robertson LJ, Gjerde BK: Effects of the Norwegian winter environment on Giardia cysts and Cryptosporidium oocysts. Microb Ecol 2004, 47:359-365.

30. Birkelo CP: Pharmaceuticals, direct-fed microbials, and enzymes for enhancing growth and feed efficiency of beef. Vet Clin North Am Food Anim Pract 2003, 19:599-624.

31. van Schaik G, Rossiter CR, Stehman SM, Shin SJ, Schukken YH: Longitudinal study to investigate variation in results of repeated ELISA and culture of fecal samples for Mycobacterium avium subsp paratuberculosis in commercial dairy herds. Am J Vet Res 2003, 64:479-484.

32. Bach SJ, Selinger LJ, Stanford K, McAllister TA: Effect of supplementing corn- or barley-based feedlot diets with canola oil on faecal shedding of Escherichia coli O157:H7 by steers. J Appl Microbiol 2005, 98:464-475.

33. Collins MT, Wells SJ, Petrini KR, Collins JE, Schultz RD, Whitlock RH: Evaluation of five antibody detection tests for diagnosis of bovine paratuberculosis. Clin Diagn Lab Immunol 2005, | 2:685-692.

34. Matthews L, McKendrick IJ, Ternent H, Gunn GJ, Synge B, Woolhouse ME: Super-shedding cattle and the transmission dynamics of Escherichia coli OI57. Epidemiol Infect 2006, 134:131-| 42.

35. Cobbold RN, Hancock DD, Rice DH, Berg J, Stilborn R, Hovde C], Besser TE: Rectoanal junction colonization of feedlot cattle by Escherichia coli 0 157:H7 and its association with supershedders and excretion dynamics. Appl Environ Microbiol 2007, 73:1563-1568

Publish with Biomed Central and every scientist can read your work free of charge

"BioMed Central will be the most significant development for disseminating the results of biomedical research in our lifetime. "

Sir Paul Nurse, Cancer Research UK

Your research papers will be:

- available free of charge to the entire biomedical community

- peer reviewed and published immediately upon acceptance

- cited in PubMed and archived on PubMed Central

- yours - you keep the copyright
BioMedcentral 